\title{
Knowledge and Awareness on Gynaecological Issues Among Female Housekeepers - A Survey
}

\author{
Tasleem Abitha S1, Gayathri. R² and Vishnu Priya.V ${ }^{3}$ \\ ${ }^{1}$ Saveetha Dental College and Hospitals Saveetha Institute of Medical \\ and Technical Science (SIMATS) Saveetha University Chennai 77, India \\ ${ }^{2}$ Assistant Professor Department of Biochemistry Saveetha Dental College and Hospitals Saveetha \\ Institute of Medical and Technical Science (SIMATS) Saveetha University Chennai 77, India \\ ${ }^{3}$ Professor Department of biochemistry Saveetha Dental College and Hospitals Saveetha Institute \\ of Medical and Technical Science (SIMATS) Saveetha University Chennai 77, India
}

\section{ABSTRACT}

With the typical age at menopause being between the ages of 50 to 55 years, women in the geriatric age group are well into their postmenopausal phase of life. The most common gynaecological problems encountered in elderly women are vulvovaginal inflammation, genital prolapse, postmenopausal bleeding, and alterations in bladder function. To create awareness on gynaecological issues among housekeepers above 50 years. This was a survey based study and was conducted in an online forum "Google forms". This survey was taken by around 50 female housekeepers. The questionnaire was framed to evaluate the ideas and knowledge of dental students about halitosis. The information collected through the survey was analysed using SPSS and presented as descriptive statistics.The results were obtained and statistically analysed through SPSS software, chi square test was done to check the association and a p value of 0.05 was said to be statistically significant. The survey was conducted in the month of May, 2020.54 housekeepers from private dental colleges were examined for the survey out of which, 32 participants confessed that they've experienced abdominal, joint and hip pain after their 50's. According to the survey, it is noted that the majority of the housekeepers have experienced almost all of the gynaecological issues like post menopausal bleeding, vulvar disorder symptoms, difficulty in waking, etc. Hence awareness regarding self care and proper maintenance of their own self was given in this survey like dietary changes, regular exercises, maintaining a healthy weight, surrounding themselves with right people and less stress to make them understand that' Menopause is not an illness, it's just a natural part of life

KEY WORDS: HOUSEKEEPERS, HEALTH ISSUES, OLDER AGE, PROPER MAINTENANCE, SELF CARE.

\section{ARTICLE INFORMATION}

*Corresponding Author: gayathri.sdc@saveetha.com

Received 10th June 2020 Accepted after revision 6th August 2020

Print ISSN: 0974-6455 Online ISSN: 2321-4007 CODEN: BBRCBA

Thomson Reuters ISI Web of Science Clarivate Analytics USA and Crossref Indexed Journal

$$
\begin{aligned}
& \text { Clarivate } \\
& \text { Analytics }
\end{aligned}
$$

NAAS Journal Score 2020 (4.31) SJIF: 2020 (7.728)

A Society of Science and Nature Publication,

Bhopal India 2020. All rights reserved.

Online Contents Available at: http//www.bbrc.in/

Doi: $h t t p: / / d x . d o i . o r g / 10.21786 / b b r c / 13.7 / 64$ 


\section{INTRODUCTION}

With the typical age at menopause being between the ages of 50 to 55 years, women in the geriatric age group are well into their postmenopausal phase of life (HaimovKochman, Sciaky-Tamir and Hurwitz, 2005; Rowe, 2008). As women age, they face a variety of comorbid medical problems as well as gynaecological problems that may differ from those of younger women (Rowe, 2008)(Wu et al., 2019). It is important that primary care clinicians be aware of common gynaecological concerns and the potential impact of these on the function and quality of life of older women (Howell, 2002). For example, genitourinary problems can significantly affect daily function, self-esteem, well being, and even longevity in elderly women (Howell, 2002; Ponnulakshmi et al., 2019). The most common gynaecological problems encountered in elderly women are vulvovaginal inflammation, genital prolapse, postmenopausal bleeding, and alterations in bladder function (Ke et al., 2019)(Ma et al., 2019).

Low-income, ethnic minority females also encounter economic and other barriers to cancer care and an association between economic stress and depressive symptoms has been found for older females. The reproductive system of women is very complex and an unhealthy lifestyle and ignorance can cause more trouble to it (Li et al., 2020)(Chen et al., 2019). Lower back pain is one of the common symptoms of gynecological problems (Wang et al., 2019). Since the ovaries and uterus are located near the spinal cord, the back gets affected very quickly whenever something goes out of the place (Roter, 1999). The majority of the female housekeepers mainly undergo back pain in their early 50s, which is all due to:

Urinary tract infection (UTI): UTI is a condition caused due to infection in the urinary tract like urinary bladder, urethra, kidneys, etc (Gan et al., 2019). The infection is caused mainly due to bacteria, but fungi and viruses are also responsible.

Pregnancy: Body goes through a lot of changes, which sometimes may not be good. Back pain is one such problem, which is inevitable during pregnancy (Rengasamy et al., 2018). The womb grows bigger with the increase in the weight of the baby and creates a lot of pressure on the spinal cord causing back pain (Ma et al., 2019).

Ectopic Pregnancy: Being pregnant is a different feeling a woman gets in her lifetime, but it can be a dreadful experience as well (G et al., 2018). Fertilization of eggs in the fallopian tube without getting implanted in the uterus is the major cause of ectopic pregnancy and its complications.(Rengasamy et al., 2016).

Reactive Arthritis: Inflammation in joints is one of the main symptoms of reactive arthritis (Gerber and Lo Sasso, 2006; Rengasamy et al., 2016). Infection transmitted sexually can be a major reason for the inflammation in the joints. The disorder is not dreadful but it causes severe back pain (Juraskova et al., 2003).

Cervical Cancer: Cancer, as we all know, is a lifethreatening disease where there is an abnormal growth of cells in a specific organ spreading all across the body (Menon, V and Gayathri, 2016). Cervical cancer is one such form of cancer occurring in the cervix causing tremendous back pain followed by unusual discharge (Jainu, Priya and Mohan, 2018)(Mohan, Veeraraghavan and Jainu, 2015). These are some of the gynaecological problems, which cause severe back pain among older females often leading towards life-threatening diseases (Shukri et al., 2016). Hence, this study was conducted to create awareness on gynaecological issues among housekeepers above 50 years.

\section{MATERIAL AND METHODS}

This was a survey-based study and conducted in an online forum, google forms. This survey was taken by 54 housekeepers above 50 years from private dental college. The questionnaire consisted of 15 questions. The questions were framed to evaluate the knowledge and awareness on gynaecological issues among female housekeepers.

Data Collection: The collected answers from the questionnaire were tabulated in an excel sheet and using SPSS software the results were obtained. The results were obtained and statistically analysed through SPSS software, chi square test was done to check the association and a p value of 0.05 was said to be statistically significant. The survey was conducted in the month of January, 2020.

Sampling: 50 housekeepers who do everyday work.

A customized examination was used to collect data and a specific table for collected data records was prepared.

Ethical approval: The study protocol was approved by the institutional review board and ethical approval was obtained. All data were analyzed by multiple logistics regression analysis using SPSS software version, inference of the study is given below.

\section{RESULTS AND DISCUSSION}

54 housekeepers from private dental colleges were examined for the survey out of which the majority of the females were at the age between 55-60 years. When the question regarding diet in their regular life was asked, it was noted that half the individuals around 27 out 54 confessed that they maintain a proper food diet while the rest were not able to maintain a good diet due to their financial issues (Figure 1) (Bodurka and Sun, 2006).

As we all know pregnancy plays one of the most important roles in every woman's life, because only the proper care and our lifestyle changes after pregnancy 
in a female will define how her health is going to be for the rest of their life's (Hartmann et al., 2004; Brotto et al., 2008). When it was examined regarding the number of pregnancies among housekeepers it was noted that, majority of women had three pregnancies (Figure 2).

Figure 1: The bar graph depicts the response to the given question "Do you maintain a proper diet ?". $\mathrm{X}$ axis represents the type of response to the question and $\mathrm{Y}$ axis represents the number of participants who told Yes (Blue) and No (Green). The participants have given an equal response that 50\% of them have answered yes and 50\% of them have answered no.

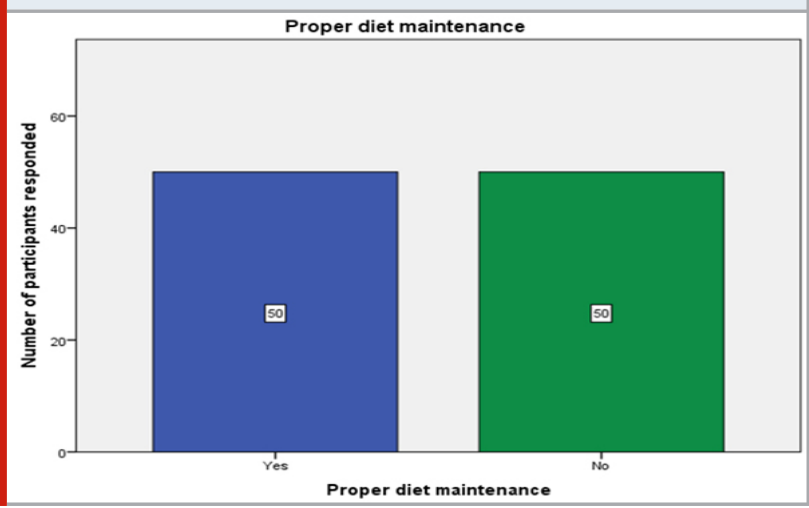

Figure 2: The bar graph depicts the response to the given question "How many pregnancies you had ?". X axis represents the type of response to the question and $\mathrm{Y}$ axis represents the number of participants who told One (Violet), Two (Red), Three (Green) and Four (Orange). Majority of the participants (50\%) have undergone three pregnancies.

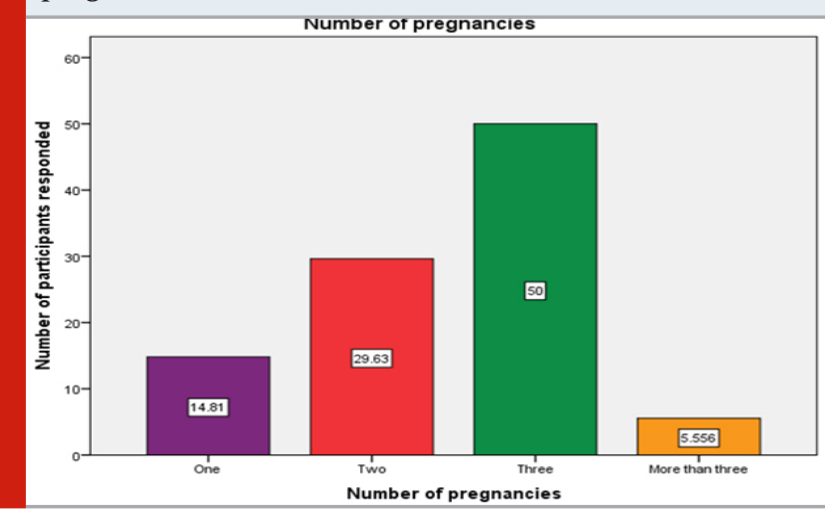

Out of 54, 32 participants confessed that they've experienced abdominal, joint and hip pain after their 50's (Figure 3). From this it was well noted that the amount of work done by housekeepers in their everyday life is the main reason for the health issues (Creasman, 2005; Ussher, Chrisler and Perz, 2019). Correlation between the age and the number of participants experienced abdominal or joint pain was done and the $\mathrm{P}$ value was found to be $0.270>0.05$, which is statistically not significant (Figure 5).
Figure 3: The bar graph depicts the response to the given question "Have you experienced abdominal or joint pain ?". X axis represents the type of response to the question and $\mathrm{Y}$ axis represents the number of participants who told Yes (Blue) and No (Green). Majority of the participants $(59.26 \%)$ have experienced abdominal or joint pain.



Figure 4: The bar graph depicts the response to the given question "Have you undergone any depression or mood swings recently ?". X axis represents the type of response to the question and $\mathrm{Y}$ axis represents the number of participants who told Yes (Blue) and No (Green). Majority of the participants (72.22\%) have undergone depression or mood swings recently.

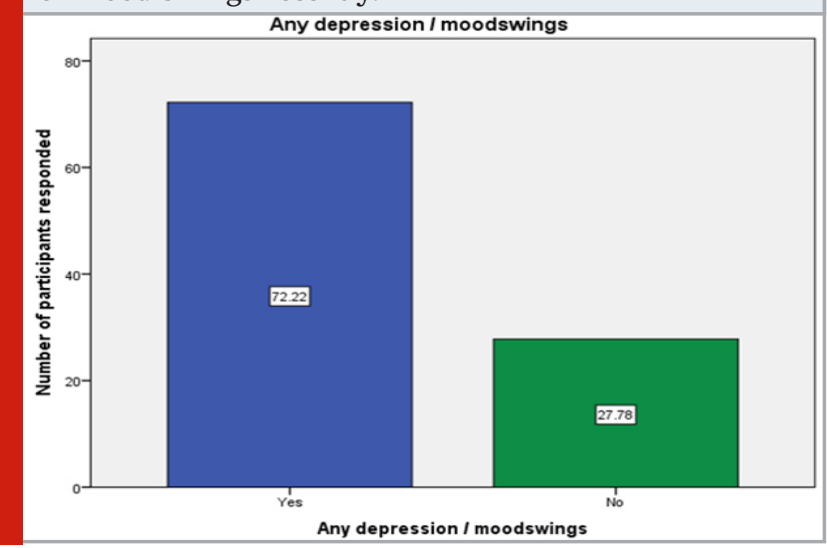

Also when a proper diet is not maintained by a female it will definitely lead to weakness of the body, which eventually leads to problems in their periods (Creasman et al., 1987). Hence from the current study it was seen that around 35 participants out of 54 have undergone irregular periods before their menopause. And also 40 participants out of 54 have already undergone their menopause (Lee et al., 2006). Correlation between the age and the number of participants who have undergone menopause was done and $\mathrm{P}$ value was found to be 0.098 $>0.05$, which is statistically not significant (Figure 6).

Post menopausal bleeding is not something very common which usually occurs due to thinning of vaginal lining or womb lining or due to side effects of some medications, which is experienced by 34 out of 54 participants in the current study (Gerber and Lo Sasso, 2006). 
Figure 5: The bar graph represents the association between the age and their responses to the question. $\mathrm{X}$ axis represents the age of the participants and $\mathrm{Y}$ axis represents the number of responses, Yes (Blue) and No (Green). Higher number of participants above 60 years $(28.30 \%)$ and 55 - 60 years participants (18.87\%) have answered that they have experienced abdominal or joint pains. Chi square analysis was done ( $\mathrm{P}$ value was found to be $0.270>0.05$, which is statistically not significant. There was no significant difference between the age and the response to the question asked.

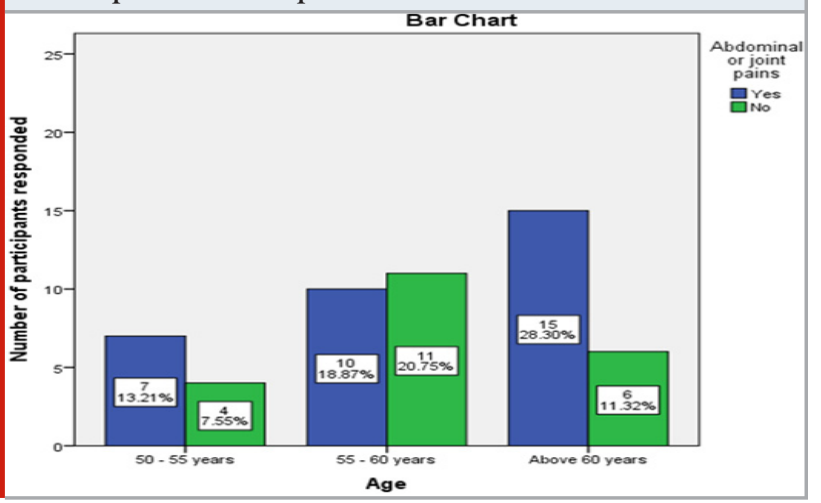

Figure 6 - The bar graph represents the association between the age and their responses to whether they have undergone menopause.. $\mathrm{X}$ axis represents the age of the participants and $\mathrm{Y}$ axis represents the number of responses, Yes (Blue) and No (Green). Higher number of participants above 60 years $(35.85 \%)$ and 55 - 60 years participants $(24.53 \%)$ have answered that they have undergone menopause. Chi square analysis was done ( $\mathrm{P}$ value was found to be $0.098>0.05$, which is statistically not significant. There was no significant difference between the age and the response to the question asked.

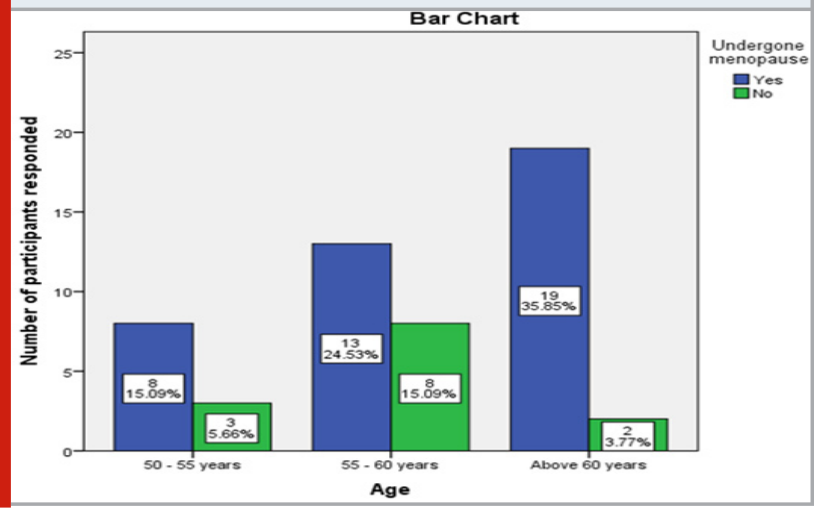

And also it was noted that the majority of the participants have experienced vulvar disorder symptoms like burning and pain most often, also less often itching and bleeding. Majorly females above 50s have hypertension and diabetes which is also one of the main causes for gynaecological issues and it is noted in the current study (Gerber and Lo Sasso, 2006). Correlation between the age and the number of participants who have any systemic disease was done and $\mathrm{P}$ value was found to be 0.279 > 0.05 , which is statistically not significant (Figure 7).

Figure 7: The bar graph represents the association between the age and their responses to whether they suffer from diabetes or hypertension. $\mathrm{X}$ axis represents the age of the participants and $\mathrm{Y}$ axis represents the number of responses, Yes (Blue) and No (Green). Higher number of participants above 60 years $(28.30 \%)$ and 55 - 60 years participants $(18.87 \%)$ have answered that they have systemic diseases like hypertension and diabetes. Chi square analysis was done (P value was found to be 0.279 $>0.05$, which is statistically not significant. There was no significant difference between the age and the response to the question asked.

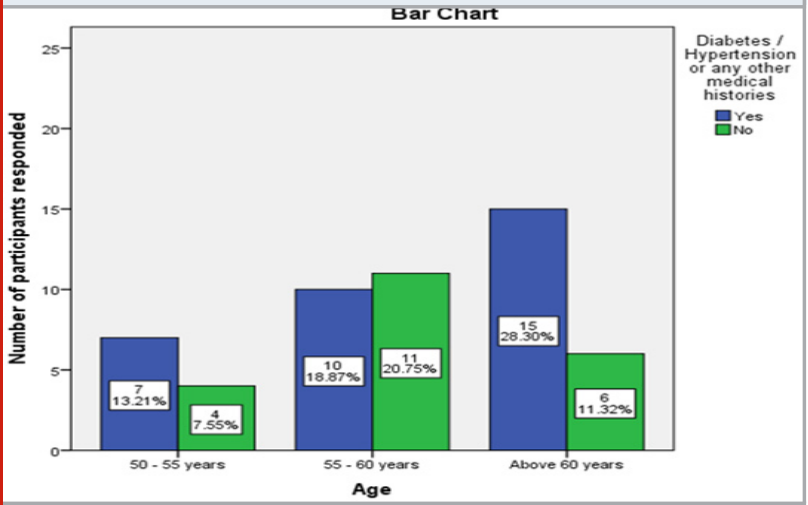

Figure 8: The bar graph represents the association between the age and their responses to whether they suffer from depression or mood swings. $X$ axis represents the age of the participants and $\mathrm{Y}$ axis represents the number of responses, Yes (Blue) and No (Green). Higher number of participants above 60 years (35.85\%) and 55 - 60 years participants $(24.53 \%)$ have answered that they have recently undergone depression which is due to menopause. Chi square analysis was done ( $P$ value was found to be $0.077>0.05$, which is statistically not significant. There was no significant difference between the age and the response to the question asked.

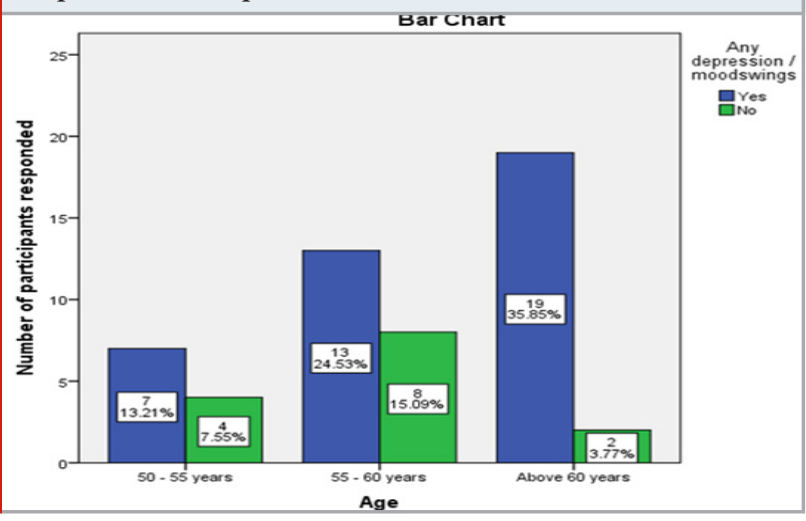

And the surprising event noted from the survey is, around $72.2 \%$ of the housekeepers undergo depression and mood swings after their 50's, which to their shock reveals that 
it is due to the menopause they're undergoing and not due to their age (Figure 4). Correlation between the age and the number of participants who have undergone any depression or mood swings was done and $\mathrm{P}$ value was found to be $0.077>0.05$, which is statistically not significant (Figure 8).

Stress and anxiety is one the major life threatening pain that every individual in their lifetime at least once will they undergo. Definitely a female above 50 years will have a history of depression, discouragement and hopelessness that most of us will not note down (Elsaie et al., 2016). That too when it comes as housekeepers, it might affect their piece of mind a lot more because of the family and financial problems they face everyday which is also one of the major reasons for the gynaecological issues they face after their menopause.

Analysed from the previous study it is noted that, majority of the older females undergo gynaecological issues especially in the time of menopause, majorly due to stress and depression which only can be corrected by their family support and lifestyle changes (Stiles et al., 2012).

\section{CONCLUSION}

From the study it is noted that, around the majority of the women undergo sorrowful and cheerless lifestyles once they enter the menopause. The reason to sort out housekeepers in this survey is that unprivileged women like them need more acknowledgement to fight this burdensome world with great strength. Hence awareness regarding self care and proper maintenance of their own self was given in this survey like dietary changes, regular exercises, maintaining a healthy weight, surrounding themselves with right people and less stress to make them understand that' Menopause is not an illness, it's just a natural part of life. Though its symptoms can be difficult to deal with, eating the right diet and exercising regularly may help alleviate and prevent them from getting stressed.

\section{ACKNOWLEDGEMENTS}

The authors would like to thank the study participants for their participation and kind cooperation throughout the study

Conflict of Interest: The authors declare that there were no conflicts of interest in the present study

\section{REFERENCES}

Bodurka, D. C. and Sun, C. C. (2006) 'Sexual Function after Gynecologic Cancer', Obstetrics and Gynecology Clinics of North America, pp. 621-630. doi: 10.1016/j. ogc.2006.09.006.

Brotto, L. A. et al. (2008) 'A Psychoeducational Intervention for Sexual Dysfunction in Women with Gynecologic Cancer', Archives of Sexual Behavior, pp. 317-329. doi: 10.1007/s 10508-007-9196-x.
Chen, F. et al. (2019) '6-shogaol, a active constiuents of ginger prevents UVB radiation mediated inflammation and oxidative stress through modulating $\mathrm{NrF} 2$ signaling in human epidermal keratinocytes (HaCaT cells)', Journal of Photochemistry and Photobiology B: Biology, p. 111518. doi: 10.1016/j.jphotobiol.2019.111518.

Creasman, W. T. et al. (1987) 'Estrogen replacement therapy in the patient treated for endometrial cancer', International Journal of Gynecology \&t Obstetrics, pp. 265-265. doi: 10.1016/0020-7292(87)90264-5.

Creasman, W. T. (2005) 'Hormone replacement therapy after cancers', Current Opinion in Internal Medicine, pp. 655-661. doi: 10.1097/01.cco.0000174034.62032.08.

Elsaie, L. et al. (2016) 'Effectiveness of topical peppermint oil on symptomatic treatment of chronic pruritus', Clinical, Cosmetic and Investigational Dermatology, pp. 333-338. doi: 10.2147/ccid.s116995.

Gan, H. et al. (2019) 'Zingerone induced caspasedependent apoptosis in MCF-7 cells and prevents 7,12-dimethylbenz(a)anthracene-induced mammary carcinogenesis in experimental rats', Journal of biochemical and molecular toxicology, 33(10), p. e22387.

Gerber, S. E. and Lo Sasso, A. T. (2006) 'The evolving gender gap in general obstetrics and gynecology', American Journal of Obstetrics and Gynecology, pp. 1427-1430. doi: 10.1016/j.ajog.2006.07.043.

G, R. et al. (2018) 'CYTOTOXICITY OF STRAWBERRY EXTRACT ON ORAL CANCER CELL LINE', Asian Journal of Pharmaceutical and Clinical Research, p. 353. doi: 10.22159/ajpcr.2018.v11i9.25955.

Haimov-Kochman, R., Sciaky-Tamir, Y. and Hurwitz, A. (2005) 'Reproduction concepts and practices in ancient Egypt mirrored by modern medicine', European Journal of Obstetrics \&t Gynecology and Reproductive Biology, pp. 3-8. doi: 10.1016/j.ejogrb.2005.03.022.

Hartmann, U. et al. (2004) 'Low sexual desire in midlife and older women: personality factors, psychosocial development, present sexuality', Menopause, pp. 726-740. doi: 10.1097/01.gme.0000143705.42486.33. Howell, E. (2002) 'Do women prefer female obstetricians?', Obstetrics \& Gynecology, pp. 1031-1035. doi: 10.1016/ s0029-7844(02)01980-4.

Jainu, M., Priya, V. and Mohan, S. (2018) 'Biochemical evidence for the antitumor potential of Garcinia mangostana Linn. On diethylnitrosamine-induced hepatic carcinoma', Pharmacognosy Magazine, p. 186. doi: 10.4103/pm.pm_213_17.

Juraskova, I. et al. (2003) 'Post-treatment sexual adjustment following cervical and endometrial cancer: a qualitative insight', Psycho-Oncology, pp. 267-279. doi: 10.1002/pon.639.

Ke, Y. et al. (2019) 'Photosynthesized gold nanoparticles 
from Catharanthus roseus induces caspase-mediated apoptosis in cervical cancer cells (HeLa)', Artificial Cells, Nanomedicine, and Biotechnology, pp. 1938-1946. doi: 10.1080/21691401.2019.1614017.

Lee, K.-B. et al. (2006) 'Endometrial cancer patients and tibolone: A matched case-control study', Maturitas, pp. 264-269. doi: 10.1016/j.maturitas.2006.03.012.

Li, Z. et al. (2020) 'Apoptotic induction and antimetastatic activity of eugenol encapsulated chitosan nanopolymer on rat glioma C6 cells via alleviating the MMP signaling pathway', Journal of Photochemistry and Photobiology B: Biology, p. 111773. doi: 10.1016/j. jphotobiol.2019.111773.

Ma, Y. et al. (2019) 'Sesame Inhibits Cell Proliferation and Induces Apoptosis through Inhibition of STAT-3 Translocation in Thyroid Cancer Cell Lines (FTC133)', Biotechnology and Bioprocess Engineering, pp. 646-652. doi: 10.1007/s12257-019-0151-1.

Menon, A., V, V. P. and Gayathri, R. (2016) 'Preliminary phytochemical analysis and cytotoxicity potential of pineapple extract of oral cancer cell lines', Asian Journal of Pharmaceutical and Clinical Research, p. 140. doi: 10.22159/ajpcr.2016.v9s2.13313.

Mohan, S. K., Veeraraghavan, V. P. and Jainu, M. (2015) 'Effect of pioglitazone, quercetin and hydroxy citric acid on extracellular matrix components in experimentally induced non-alcoholic steatohepatitis', Iranian journal of basic medical sciences, 18(8), pp. 832-836.

Ponnulakshmi, R. et al. (2019) 'In silico and in vivo analysis to identify the antidiabetic activity of beta sitosterol in adipose tissue of high fat diet and sucrose induced type-2 diabetic experimental rats', Toxicology mechanisms and methods, 29(4), pp. 276-290.

Rengasamy, G. et al. (2016) 'Characterization, Partial Purification of Alkaline Protease from Intestinal Waste of Scomberomorus Guttatus and Production of Laundry Detergent with Alkaline Protease Additive', Indian Journal of Pharmaceutical Education and Research, 50(2s). Available at: https://www.ijper.org/article/413 (Accessed: 29 June 2020).

Rengasamy, G. et al. (2018) 'Cytotoxic and apoptotic potential of Myristica fragrans Houtt. (mace) extract on human oral epidermal carcinoma KB cell lines', Brazilian Journal of Pharmaceutical Sciences. doi: 10.1590/s217597902018000318028.

Roter, D. (1999) 'Effects of obstetrician gender on communication and patient satisfaction*1', Obstetrics Et Gynecology, pp. 635-641. doi: 10.1016/s00297844(98)00542-0.

Rowe, T. (2008) 'The Male Medical Student Problem', Journal of Obstetrics and Gynaecology Canada, pp. 873-874. doi: 10.1016/s1701-2163(16)32964-4.

Shukri, N. M. M. et al. (2016) 'Awareness in childhood obesity', Research Journal of Pharmacy and Technology, p. 1658. doi: 10.5958/0974-360x.2016.00334.6.

Stiles, M. et al. (2012) 'Gynecologic Issues in Geriatric Women', Journal of Women's Health, pp. 4-9. doi: 10.1089/jwh.2011.2803.

Ussher, J. M., Chrisler, J. C. and Perz, J. (2019) Routledge International Handbook of Women's Sexual and Reproductive Health. Routledge.

Wang, Y. et al. (2019) 'Synthesis of Zinc oxide nanoparticles from Marsdenia tenacissima inhibits the cell proliferation and induces apoptosis in laryngeal cancer cells (Hep-2)', Journal of photochemistry and photobiology. B, Biology, 201, p. 111624.

$\mathrm{Wu}$, F. et al. (2019) 'Biologically synthesized green gold nanoparticles from Siberian ginseng induce growth-inhibitory effect on melanoma cells (B16)', Artificial Cells, Nanomedicine, and Biotechnology, pp. 3297-3305. doi: 10.1080/21691401.2019.1647224. 